\title{
Are We at a Watershed Moment for the Quantitative Literacy Movement?: Review of Shifting Context, Stable Core: Advancing Quantitative Literacy in Higher Education, by Luke Tunstall, Gizem Karaali, and Victor Piercey, eds.
}

Maura Mast

Fordham University, mmast@fordham.edu

Follow this and additional works at: https://digitalcommons.usf.edu/numeracy

Part of the Other Mathematics Commons, and the Scholarship of Teaching and Learning Commons

\section{Recommended Citation}

Mast, Maura. "Are We at a Watershed Moment for the Quantitative Literacy Movement?: Review of Shifting Context, Stable Core: Advancing Quantitative Literacy in Higher Education, by Luke Tunstall, Gizem Karaali, and Victor Piercey, eds.." Numeracy 12, Iss. 2 (2019): Article 14. DOI: https://doi.org/10.5038/ 1936-4660.12.2.14 


\title{
Are We at a Watershed Moment for the Quantitative Literacy Movement?: Review of Shifting Context, Stable Core: Advancing Quantitative Literacy in Higher Education, by Luke Tunstall, Gizem Karaali, and Victor Piercey, eds.
}

\begin{abstract}
Luke Tunstall, Gizem Karaali, and Victor Piercey, eds. 2019. Shifting Concepts, Stable Core: Advancing Quantitative Literacy in Higher Education. Math Notes 88. (Mathematics Association of America, MAA Press). Print ISBN 978-0-88385-198-2. Electronic ISBN 978-1-61444-324-7.

The thematic approach of the edited MAA Notes volume Shifting Contexts, Stable Core: Advancing Quantitative Literacy in Higher Education is that the "construct" of quantitative literacy is now fairly stable, but the contexts in which quantitative literacy is taught (and practiced) continue to change. Several chapters give the reader much to consider regarding what constitutes the foundation of this stable core and, relatedly, how quantitative literacy is defined. Still, the depth and range of contributions in this book provide strong evidence that quantitative literacy has matured and is thriving in higher education. The approximately twenty chapters include retrospectives on the history of quantitative literacy (primarily in the United States), as well as perspectives on its current state; both lessons and "lessons learned" about teaching quantitative literacy in mathematical and interdisciplinary contexts; discussions of assessment; and critical reflections of the relationship between quantitative literacy and social justice. This rich and, at times, provocative book is an excellent addition to the growing collection of quantitative literacy scholarship.
\end{abstract}

\section{Keywords}

quantitative literacy, quantitative reasoning, numeracy, higher education, assessment

\section{Creative Commons License}

$$
\text { c) (7) (8) }
$$

This work is licensed under a Creative Commons Attribution-Noncommercial 4.0 License

\section{Cover Page Footnote}

Maura Mast is Dean of Fordham College at Rose Hill, a liberal arts college in the Bronx that is part of Fordham University. She has held visiting positions in mathematics at Wellesley College, the University of Notre Dame, and Northeastern University. Prior to joining Fordham, she was a faculty member in mathematics at the University of Massachusetts Boston and served in several administrative positions; her responsibilities included oversight the university's quantitative reasoning program. Dr. Mast has held leadership roles in the Association for Women in Mathematics, the Joint Committee for Women in Mathematics, and SIGMAA-QL. Her textbook Common Sense Mathematics, co-authored with Ethan Bolker, was published by the Mathematical Association of America in 2016. 


\section{Introduction}

Published in 2001, the book Mathematics and Democracy: The Case for Quantitative Literacy presented a compelling argument for quantitative literacy ${ }^{1}$. The authors echoed earlier calls for quantitative literacy as an imperative for college students (see, for example, Sons 1994), but brought an almost visceral urgency to their case statement with repeated references to a world that is increasingly quantitative and ever more reliant on technology, data, and numbers in context.

As the authors in the MAA Notes volume Shifting Contexts, Stable Core: Advancing Quantitative Literacy in Higher Education make clear, the narrative has now shifted (and the world is even more technological and quantitative): quantitative literacy has matured and is thriving. In this book, a sequel to both Mathematics and Democracy and the 2006 MAA Notes volume Current Practices in Quantitative Literacy, the authors no longer need to make the case for quantitative literacy. Instead, they turn their attention to deep - and at times difficult - questions of how quantitative literacy is defined and situated within mathematics and other disciplines; they reflect on the current state of quantitative literacy, including how it is taught and assessed; and they challenge readers to a fresh reconsideration of the relationship between quantitative literacy and social justice. With chapters that will be of interest to both the new and the experienced members of the quantitative literacy community, this book is an excellent addition to the growing collection of quantitative literacy scholarship.

The editors organize this volume into four sections, providing brief overviews that make connections within each part. The first section presents a high-level perspective of quantitative literacy, including discussions of the history and vision of quantitative literacy and an assessment of its current state. This section also includes a proposed definition of quantitative literacy, one which appears often throughout the book. The second section offers examples and guidance regarding the development and implementation of quantitative literacy curricula. In the third section, the context shifts from implementing quantitative literacy in the classroom to implementing it at an institutional level; assessment of quantitative literacy is also addressed. The fourth section includes a varied set of reflections about quantitative literacy, ending with an interview with Len Vacher, one of the editors of the journal Numeracy. I'll note that the editors overlay a metaphor of a visit to "Quantitative Literacy University" onto their organizational structure. This metaphorical conceit gets a bit strained and doesn't seem necessary.

\footnotetext{
${ }^{1}$ A note about terminology. Not surprisingly, different authors in this volume make different choices from among the terms numeracy, $Q L / Q R$, quantitative literacy, and quantitative reasoning. The term "quantitative literacy" appears most frequently in the book and so that's what I will use in this review. See Vacher (2014), Karaali et al. (2016), and Vacher (2019) for some data-driven reflections about these nomenclatural issues.
} 
I read the book with the larger conversation about the relationships among quantitative literacy, mathematics, and interdisciplinarity in mind and found myself mentally sorting the chapters according to how they addressed this relationship; I'll use this approach in my organization of this review. (Of course, this is just one of many ways to approach this rich set of essays.) From this perspective, I'll begin with an analysis of how this volume discusses the history and current state of quantitative literacy and presents a new definition of quantitative literacy. This definition, and the larger relationships among quantitative literacy, mathematics, and other disciplines, is relevant to the many chapters in Shifting Contexts that address teaching and learning quantitative literacy. These chapters could be organized - perhaps not perfectly - into two groups, one which situates quantitative literacy within the mathematics classroom and another which situates it in an interdisciplinary context. The chapters discussing assessment offer another lens through which to consider the quantitative literacy/mathematics/interdisciplinarity relationship. Finally, several authors present a forceful (re)consideration of how quantitative literacy is connected to issues of social justice.

\section{What is Quantitative Literacy (and What it Could Be)}

Many of the authors in Shifting Contexts reflect on the history of the quantitative literacy movement, often as a context for their own involvement. Two chapters in particular provide not just excellent retrospectives of how approaches to quantitative literacy have evolved over the past several decades, but reflections on where the subject is now and where it could be going. These chapters are good companions to the chapters that attempt to articulate a definition and interpretation of quantitative literacy that is based in disciplines other than mathematics. Madison's chapter is an excellent starting point for a consideration of what quantitative literacy was, is, and could be. In his essay, he outlines several of the issues that occupied the quantitative literacy community early on, including the question of defining quantitative literacy and articulating its relationship to mathematics (and to mathematicians). He acknowledges the difficulty of explaining quantitative literacy to others (especially those outside of academia), noting that "many of us in the QL community ... have moved beyond trying to define QL ... and have accepted that QL/QR is what it is and worthy of support, further study, and development." (p. 37). Summing up the current state of quantitative literacy, Madison acknowledges that while there is no "canonical" course at the college level, there is a growing and diverse set of offerings under the quantitative literacy umbrella. He points to other ways in which quantitative literacy has evolved: the emergence of formal structures such as campus-based quantitative literacy support centers, professional organizations with a partial or whole focus on quantitative literacy, and multi-year, grant-funded projects; the development of the journal 
Numeracy as a vehicle for the scholarship of quantitative literacy; and the growing interdisciplinary nature of quantitative literacy. From Madison's perspective, the question is no longer one of what quantitative literacy is but a question of how it can be achieved and flourish in this new phase.

Karaali's interview with Len Vacher, which appears as the last chapter of Shifting Contexts, is a good partner to Madison's in that it presents a long view of quantitative literacy's development and an optimism for its future. Other people may know Vacher for his excellence in teaching and research in geology; like many others in the quantitative literacy community, I am more familiar with his passionate commitment to both quantitative literacy and interdisciplinarity. Vacher provides what the interviewer calls a "significant perspective." For example, Vacher asserts that "Quantitative literacy is too big of a field to leave to the mathematicians to develop.... [It is] not going to work unless the rest of the academic world is involved as well" (p. 229). This rich, very personal reflection covers a lot of ground and the careful reader will see echoes of many of the chapters in this book here - not because Vacher read those chapters, I imagine, but because he thinks so expansively.

With the Madison and Karaali chapters as solid context, I recommend that the reader who is interested in the serious question of what quantitative literacy is and could be - read (and perhaps reread) the chapters by Fisher, Craig et al., and Cardetti et al. The challenge of defining quantitative literacy has been a subject of much conversation over the past several decades. Ganter's introductory essay in this volume describes the approach taken in Mathematics and Democracy: The Case for Quantitative Literacy. She writes, "In lieu of a seemingly-unattainable definition, the design team chose instead to focus on elements, expressions, skills, and challenges of QL" (p. ix). This focus on common themes freed the authors to think creatively, allowing them to free quantitative literacy from mathematics. In his introduction to Current Practices in Quantitative Literacy, Gillman (2006) acknowledged the difficulty of defining quantitative literacy. First asserting that it "is one of those things about which we say "I know it when I see it"" (p. vii), he then invoked the definition formulated by SIGMAA-QL, the MAA's Special Interest Group on Quantitative Literacy: "the ability to adequately use elementary mathematical tools to interpret and manipulate quantitative data and ideas that arise in individuals' private, civic, and work lives.... [,it] is a habit of mind" (p. vii). Ten years later, Karaali et al. (2016) took stock of the diversity of terms and definitions, conducting a frequency analysis of the terms and a review of varied approaches to the definition. They concluded that "there is indeed a common thread, that of competence in interacting with myriad mathematical and statistical representations of the real world, in the contexts of daily life, work situations, and civic life" (p. 25). They chose not to provide a formal definition, instead expressing hope that their work would be helpful in clarifying the ideas inherent in these terms. 
The point in reviewing all of this scholarly history is to illustrate just how challenging it has been to develop a definition of quantitative literacy. In his chapter, Fisher takes on this challenge, using a social linguistics approach and building a cohesive connection between quantitative literacy and reading/writing literacy, while also arguing that literacy is "an inherently social phenomenon, and we cannot divorce the study of QL from the social contexts in which it is realized" (p. 4). To develop his definition, Fisher first explores how numbers are a form of "technology of comprehension": our use of numbers impacts how we perceive the world, and this perception has evolved over time as the utilization of numbers has evolved. He asserts that culture is a mediator and that "the technologies of mathematics are constructed with the practices of specific social groups in mind, and again, one needs to be aware of these practices to use numbers" (p. 6). There is a lot to digest in this chapter - Fisher digs deeply into what we mean (or think we mean) when we talk about literacy and quantitative literacy, how this conception may be connected to mathematics, and how it is socially constructed. He then leads the reader logically to his suggested definition: "Quantitative literacy is the facility to participate in the intersecting quantitative practices of many different communities (each with their own patterns of discourse)" (p. 10) and presents a robust, if at times strained, defense of this definition. I'm not as familiar with social linguistics as Fisher clearly is. I appreciated how eloquently he explained his approach, but I felt the urge to do additional research so that I could really understand this argument. I do agree with much of what Fisher says, including his emphasis on social contexts, a "shared burden" for teaching quantitative literacy, and his inclusion of "technologies of comprehension" in approaching quantitative literacy. Still, I found it difficult to embrace this definition, in part because it struck me as ambiguous and relativistic. It's not clear which communities (or how many) and which quantitative practices to include in determining this "facility". The editors of this volume reference this definition and suggest that it represents the "foundation of the stable core" of quantitative literacy. I'd prefer to see more robust discussion within the quantitative literacy community about this definition and its implications before moving in this direction.

Reading the chapter by Craig, Mehta, and Howard, I again felt the urge to do external research, in this case in the area of New Literacy Studies (see, perhaps, Gee 2010). Consistent with Fisher, they view quantitative literacy as a social practice. They also argue against the "common deficit perspective taken toward quantitative literacies" (p. 16), a point echoed by Philip and Rubel in this book. Craig et al. take the approach that as technologies change, quantitative literacy doesn't just translate, in a static form, into the new technology. Instead, quantitative literacy itself changes. They call these "new quantitative literacies - the social and cultural practices and interactions that co-emerge with use and creation of quantitative information" (p. 17). Using a media framework focused on the 
dimensions of access, analysis, evaluation, and content creation, the authors "reimagine quantitative literacy in each dimension." In addition to this analysis, they note the challenges of these new quantitative literacies, including how they may be used in deceptive ways to advance particular agendas. Their argument that quantitative literacy has changed over time, especially as technology has changed, is compelling and thought-provoking.

The chapter by Cardetti, Wagner, and Byram follows closely from the chapters by Fisher and Craig et al., in that the authors link culture to quantitative literacy, albeit with a stronger focus on mathematics. The authors address the classroom experience and use Byram's model of Intercultural Communicative Competence and the concept of Intercultural Citizenship (see, for example, Byram 1997) as a way of supporting quantitative literacy using interdisciplinarity. As they write (p. 29),

it is especially useful to address complex real world problems requiring creative solutions and input from a variety of sources. In this way, students' intercultural competence is combined with "action in the world," which is included in intercultural citizenship, which in turn links to quantitative literacy as an "expression of just action."

They provide examples of a high-school level interdisciplinary unit that brought together Spanish and mathematics, and a college-level calculus course that integrated general chemistry into a unit on renewable energy; they also connect their approach to the work of other authors in this volume.

\section{Quantitative Literacy in a Mathematics Context (With Some Interdisciplinarity)}

Several of the authors in this volume situate quantitative literacy within a mathematics context (usually in the mathematics classroom), bringing in interdisciplinary topics or approaches as appropriate. These chapters present rich and useful examples of how mathematics-based quantitative literacy can be stretched in an interdisciplinary direction. The reader will see a clear evolution, since the publication of the Current Practices book, in how to teach quantitative literacy.

The most mathematically-oriented approach comes from Gaze, who gives an overview of how a course can be structured to meet the case for quantitative literacy as outlined in Mathematics and Democracy. He anchors his course in proportional reasoning, with the concept of ratio as a common theme, then introduces spreadsheets as a modeling tool and as a way to help students engage with complicated problems involving data. He regards statistical literacy as integral to the course, given that students will be making decisions involving chance and uncertainty for the rest of their lives. Gaze is somewhat proscriptive about the 
mathematical topics, and in fact the course is heavily mathematics-based, but he also makes it clear that "a QR course can be defined as a math class in which the context drives the content" (p. 62). From Gaze's perspective, this approach to mathematics skill-building and problem-solving in rich contexts is well aligned with Fisher's definition.

Boersma, Diefenderfer, Dingman, and Madison flip Gaze's approach, emphasizing context first and bringing in mathematics as needed. Their course is constructed using news reports, which they find to be a good "hook" for students. It's also a good "hook" for quantitative literacy, in that reading and understanding news articles requires critical thinking, critical reading, interpretation, communication - and mathematics. The authors explore how this approach can be flexible (a headline alone may motivate a good classroom discussion), topical ("news of the day"), in-depth (as part of a formal project or case study), and technology-based (using spreadsheets to explore trends or data). They also note that it can be difficult, given that "media articles can take students and instructors into unfamiliar contexts that can challenge one's own knowledge and understanding."

After three decades of trying to teach mathematics in context, Bolker developed an approach that is in spirit with the approach of Boersma et al. The motivating principle was "to think about what we hoped our students would remember and find useful ten years after they had taken the course" (p. 202). The result is a course organized by context (often from the news), with mathematics brought in as needed. ${ }^{2}$ Reflecting on his experience, Bolker observes that there have been two themes. The first is the importance of common knowledge: "When we asked students to read quotes from the daily paper or the web we found that many had trouble understanding and hence relating to the material, well before they began to struggle with the mathematical content." Addressing this challenge in class led to "digressions" into different disciplines, along with discussions about careful reading. His hope is that well after they leave the class, students will remember these moments. The second theme is that discussions of current events inevitably led to discussions of related political, moral, and ethical issues. Several chapters in this book, in particular the one by Philip and Rubel, provide perspectives on this theme.

In their quantitative literacy course, Dorée and Balbach focus on personal finance, designing "projects that expect students to examine their own personal finances through the lens of mathematics, reason carefully about choices and consequences of personal financial decision [sic], and pose intelligent questions" (p. 106). These projects were initially developed for an introductory quantitative literacy course built entirely around topics in financial mathematics; the projects could also be incorporated into other types of quantitative literacy courses. The

${ }^{2}$ Note: Bolker and I worked together to develop this course and the resulting textbook (Bolker and Mast 2016). 
authors articulate learning objectives that include the development of specific mathematics skills (compound interest, present and future value, etc.) and broader abilities (such as reasoning and communication). They describe several flexiblydesigned projects and offer some cautions about implementation.

Dewar, Larson, and Zachariah reflect on their challenges in sustaining innovation in quantitative literacy course development. They incorporated themes of civic engagement into their course, using a model of open-ended inquiry and designing the course around "semester-long group projects concerning local community or campus issues that [students] could investigate using the relatively modest set of mathematical tools developed in the QL course" (p. 141). The course needed to comply with the previously approved quantitative literacy course structure, and so they included mathematical content accordingly. The learning outcomes also wove in mathematics, with attention to helping students see the relevance and usefulness of mathematics in understanding real world problems and developing their abilities to use appropriate mathematical tools to analyze problems and make recommendations. This chapter is important for two reasons. The first is curricular, in that the course that the authors describe is interesting and innovative and is a good model for someone looking to bring together civic engagement and quantitative literacy. The second is about institutional culture, in that the authors struggled to sustain the course and persuade other mathematics faculty to teach it. As they note, "[w] hile the standard QL course had full departmental support, our particular approach was just an innovation on it undertaken by individuals" (p. 144). The authors offer excellent suggestions about how to promote and sustain innovation in course development and instruction that should be of particular value to the quantitative literacy community.

\section{Quantitative Literacy in Interdisciplinary Contexts (With Some Mathematics)}

A number of authors in Shifting Contexts explore quantitative literacy in deliberately interdisciplinary contexts, with mathematics as an integral, but less central, part of the course. Many of these authors directly reflect on how their approaches incorporate "different communities," as in Fisher's definition.

Three chapters provide overviews of how quantitative literacy can be the focus of a first-year seminar. Fung's chapter links the "reform" approach of quantitative literacy to the high-impact practice of the first-year seminar (itself a type of reform of general education). She describes the development of three interdisciplinary, discussion-based, writing-intensive courses in which students engage with the theme of data from different perspectives. She noted that in all of the seminars, "students had to get familiar with new contexts from different disciplines, such as sociology, environmental science, or politics. That is, to use the ideas of Fisher..., 
students engaged with ideas at the intersections of different communities of practice as they relate to quantitative thinking" (p. 68). Fung provides helpful detail about the course design, learning outcomes, and mathematics topics that were incorporated; the interested reader will find much to build on here. In addition, Fung is quite reflective on how developing and teaching this type of course may move a mathematics faculty member outside of their comfort zone.

Schwab-McCoy's chapter also describes a first-year seminar focused on data, in this case with an explicit emphasis on helping students develop "[q]uantitative fluency, the ability to speak naturally, conversationally, and extemporaneously about quantitative evidence" (p. 78). She links this approach to Fisher's definition by referencing language learning: "[i]n language learning, literacy leads to fluency - an innate comfort with a language and with social constructs surrounding it" (p. 78). Schwab-McCoy provides a solid overview of how quantitative fluency can be developed and how it is different from quantitative literacy. She describes her course, outlining not just the content but her approach to using popular media, including blog posts and YouTube clips, to help students understand the social construction of quantitative evidence. She notes the challenges of incorporating media (will students focus on the context and not on the quantitative literacy?) but makes a strong argument for including mainstream media in the classroom.

In their chapter, Baird, Nikbakht, Marland, and Palmer describe how to incorporate quantitative literacy into a sustainability-focused first-year seminar, building on student interest in the environment (and their institution's focus on sustainability) to develop a course connecting environmental issues to mathematics. They argue for an interdisciplinary approach to sustainability and note that many issues in sustainability can be woven into the mathematics classroom; they also connect their approach to Fisher's articulation of quantitative literacy among "social niches." One of the unexpected observations in this chapter is that sustainability can act as a "bridge" of sorts to help students in STEM disciplines see the "humanistic and social aspects of their work" and to help students outside of STEM become more comfortable with mathematics and quantitative information. As the authors observe, "[s] ustainability is an area where the classic divide between the humanities and the sciences is narrow, and the value of reaching across is fundamentally important both in our daily lives and in our society as a whole" (p. 97). They provide a number of interesting sustainability examples that incorporate mathematics; they also address how this course engages students as active learners, provides students with experiences that are relevant and meaningful, and broadens students' post-college career options.

In a very novel approach, Edwards, Melfi, and Satyam address the question of mathematical rigor in an introductory, context-rich quantitative literacy course by comparing student experiences in this course with experiences of mathematics majors in a "transitions to formal mathematics" course. Reflecting on Fisher's 
definition, they note that "there are shared characteristics related to thinking and reasoning that appear in both courses" (p. 115). They argue, through the lens of these shared characteristics, that students in both courses have a "genuinely rigorous mathematical experience." Through an analysis of tasks from both courses, the authors identify three common strands: critical reasoning and analysis, application of ideas in novel contexts, and effective communication. While it is not surprising that these strands could be included in a quantitative literacy course, this approach to establishing rigor in a quantitative literacy course is both surprising and compelling.

Parsons, Salomone, and Smith consider institutional approaches to developing and implementing quantitative literacy courses and programs, noting that these entail "... the convergence of practices in the diverse communities of educators engaged in the teaching and support of QL skills" (p. 127). They observe that programs often emerge reactively, in response to general education reform, accreditation efforts, or, more dramatically, institutional moments of crisis. They describe Hamilton College's development of a quantitative literacy program as a case study in how an institution may embark upon the process of designing and implementing a quantitative literacy program. The authors provide a list of considerations, including suggestions that stakeholders from multiple disciplines be part of the conversation from the beginning and that the role of the mathematics department be clearly articulated.

\section{Assessment of Quantitative Literacy: Good News and Bad News}

Many authors in this book suggest or reference assessment tools connected with specific approaches to describing quantitative literacy. (In particular, see the chapters by Gaze and Boersma et al.) For the reader interested in a deep dive into assessment, three chapters in this text will be useful. ${ }^{3}$

I'll note that there is good and bad news here. The good news is that these chapters provide excellent guidance and resources for the development of assessment tools. I recommend beginning with Shavelson, Mariño von Hildebrand, Zlatkin-Troitschanskaia, and Schmidt's chapter, in which the authors use EvidenceCentered Design to develop situated tasks to assess quantitative literacy. Instead of studying typical quantitative literacy assessments, they advocate for using Evidence-Centered Design in "the construction of both new innovative assessments and the adaptation of existing assessments in higher education" (p. 163). Using Karaali et al.'s (2016) “common thread" approach to defining quantitative literacy,

\footnotetext{
${ }^{3}$ The reader is also encouraged to search through past issues of Numeracy for articles addressing assessment, including the theme collection that appeared in Volume 8, Issue 1, 2015.
} 
the authors prefer a situated approach to assessment, one that is context-driven. They give an extensive description of how to construct such assessments and provide three examples, two of which were designed intentionally to assess quantitative literacy, and one of which measures quantitative literacy, even though not originally designed to do so.

The chapter by Zerr takes up the difficult question of when best to conduct assessment of quantitative literacy. He astutely notes that, "[t]he stable core of QL is faced with a need to assess students' abilities within a shifted context, one where QL once may have been viewed as primarily about mathematical ability (likely coming within a single course) toward a more nuanced and cumulatively-acquired intellectual skill" (p. 177). Furthermore, if quantitative literacy is seen as existing in multiple contexts, then the student will have multiple opportunities to engage with quantitative practices as they progress through college. Therefore, Zerr argues, assessing quantitative literacy as a student approaches the end of their college studies may better capture the interdisciplinary richness of quantitative literacy. He outlines an example of a performance task assessment involving real-world data and demanding higher-order thinking, scored by faculty from across the institution, and provides a reflection on what the institution learned from implementing this assessment.

Now for the bad news. In their chapter, Cahoon and Kiliç-Bahi note that while there has been tremendous progress with regard to understanding quantitative literacy and integrating it in the curriculum, there has not been concomitant progress in assessing quantitative literacy. In particular, they argue, many existing assessments do not assess quantitative literacy from the "common thread" perspective. The authors present an overview of current assessment approaches and a discussion of outcomes. The first example is the PISA Test of Mathematics Literacy, an international test given to 15-year olds. It's not news that the performance of students from United States in the area of mathematical literacy is below average. Whether or not the implementation of the Common Core State Standards will make a difference remains to be seen (Madison 2015). The authors engage in an extensive discussion of quantitative literacy assessments from four different institutions. Here the news is troubling. The authors conclude that these assessments indicate that "QL/QR-related curricula are mostly falling short of their desired impact. High aptitude students are succeeding on these measures, as are students in STEM majors, but what of the general population of students in nonSTEM majors" (p. 192)? In addition, while there are multiple tools available to assess quantitative literacy, no one tool is broad enough. The authors offer a comprehensive set of "future directions" for these discussions; it is a daunting set of next steps. 


\section{Quantitative Literacy and Social Justice: A Call to Action}

As I initially skimmed the table of contents, I was disappointed there wasn't a section on quantitative literacy and social justice. Like many in the quantitative literacy community, I take the two-fold approach that teaching quantitative literacy is itself a social justice activity, in that issues of social and economic justice can be explored through quantitative literacy (or mathematics), and that students have an opportunity to build quantitative literacy skills through studying social justice or, more broadly, issues of wealth, privilege, and inequality. ${ }^{4}$ Several chapters in the Shifting Context book reference the latter approach (Dewar et al., for example) and I suspect that many authors agree with the former. After closely reading (and rereading) three chapters in this book, however, I was challenged to reconsider my conceptualization of the relationship between quantitative literacy and social justice.

The chapter by Getz, Richardson, Hartzler, and Fraga Leahy is an excellent starting point, not only because it is the only chapter to explicitly address quantitative literacy in the community college context, but because it is singular in its impassioned call for expanding access to quantitative literacy for these students. The authors do not repeat the "case" for quantitative literacy; instead, they lay out in stark terms how "access to QL/QR courses is, in itself, an issue of equity" ( $p$. 153 ) in that lack of access disproportionately impacts low-income and underrepresented minority students. They present data indicating that while enrollments in quantitative literacy courses in two-year colleges have grown between 1995 and 2010, these enrollments lag far behind enrollments in college algebra courses. The authors identify the factors that need to be addressed in order to meet the challenge of "fully integrating QL/QR as a normative feature of modern higher education entry-level mathematics programs" (p. 158): limited understanding (on the part of students and advisors) about what a quantitative literacy course is; lack of consistency across these courses; and the difficulties of changing large, state-wide systems. In addition to suggesting approaches to tackling each of those issues, they offer some reflections on the more complicated questions of college readiness (also an equity issue) and how best to support underprepared students.

Two other chapters directly challenge the reader to reflect more deeply - and perhaps in new ways - about the larger discourse concerning quantitative literacy and social justice. Craig, Guzmán, and Harper focus on the limits in the current scholarship of quantitative literacy, specifically how this scholarship is "situated within an individualist ideology - the idea that individuals are solely (or at least

\footnotetext{
${ }^{4}$ See, for example, the RadicalMath website at http://www.radicalmath.org/.
} 
highly) responsible for protecting themselves and remedying their vulnerability" (p. 207). They worry that the themes of "self-reliance, self-interest, and selfpreservation" in quantitative literacy scholarship will constrain the impact of quantitative literacy. They argue that instead of an individualism approach, the quantitative literacy community should take a collectivism approach to scholarship, one that focuses on how groups use quantitative literacy for good in society. Furthermore, they argue for an activism approach, one that moves people from vulnerability to empowerment. They note that this "goal is not achievable without also creating a quantitative literacy that challenges and changes those systems and people who would take advantage of the innumerate. That is, it is not enough to educate people to survive the world without also educating them to improving the world" (p. 211).

Philip and Rubel present an even stronger challenge to the existing rhetoric of quantitative literacy scholarship. Echoing Getz et al., they state that in advocating for individuals to gain quantitative literacy, we assume "that our political and economic systems are neutral and fair, that there is equitable access to quantitative literacy, and that empowering individuals through quantitative literacy will aggregate to an improved society" (p. 215). That is, not only are we asking individuals to become quantitatively literate, but we are asking them to take on the burden of fixing structural racism, income inequality, and other deep inequities in our society. The authors emphasize the need for "new quantitative literacies" (as described by Craig et al.) and advocate for instructors to "re-envision classrooms as laboratories for democracies (Guiner 2002), or spaces of democratic participation where students purposefully use and repurpose new quantitative literacies as they engage in the complexities of collective deliberation" (p. 216). They argue for shifting the lens to a collectivist one, in which people interact with each other and use quantitative literacy in sophisticated ways. The authors present two examples (both from high school contexts) that illustrate how goals of democratic engagement, equity, and social justice were addressed in these classrooms, as well as what they learned from these experiences. The complexity of this approach is captured in their observation that "[d]eep social struggles are not problems that can be solved with the help of equations, data visualizations, or computational simulations alone; they are intricate problems that involve people as complex actors" (p. 220).

\section{Concluding Remarks}

In their opening essay, the editors make the claim that quantitative literacy has sufficiently matured so that it now has a "stable core." I agree. As Madison notes, the initial questions of what quantitative literacy is an who has responsibility for it no longer dominate. (However, see Wallace (2019) for a reflection on how these 
and other questions persist). While we may not have yet settled on a definition of quantitative literacy, there is a fairly stable understanding of what it means in practice. Still, the need for a common definition of quantitative literacy is clear. Without this foundation, students will not understand why they should learn quantitative literacy, faculty won't understand why they should teach it, administrators won't understand why they should support it (or how they can assess it), and the public (including our public officials) won't understand why they should pay for it. In Shifting Contexts, Fisher's definition is offered by the editors as a "foundation for our stable core of QL/QR" (p. xvi). As compelling as Fisher's definition is, I hope that there would be robust dialogue about whether it is or is not the best definition and if so, is it the foundation for this core. I didn't see that dialogue in these essays; instead, I saw some endorsements of the definition and, more often, fleeting references to it. I have some limited suggestions for how the quantitative literacy community may find consensus on this question. In his interview, Vacher calls for more contributions to the new "Discussions and Replies" section of the journal Numeracy (see the examples of Erickson (2019) and Hamman (2019)). This suggestion would be one way to engage more deeply with this definition, or with others. Conversations at national meetings, including National Numeracy Network and SIGMAA-QL meetings, would be another.

Moving beyond the "stable core," the authors ask the reader to consider the application of quantitative literacy in different, or shifting, contexts. It's not just that quantitative literacy is increasingly situated in interdisciplinary contexts, it's that new technologies are influencing quantitative literacy. These shifts may be challenging, especially if we are comfortable with one approach, but worth exploring if quantitative literacy teaching and learning is to remain vibrant and impactful.

This volume provides an excellent set of resources for the reader who is curious about how quantitative literacy has evolved and where it's going; it also provides clear evidence that the construct of quantitative literacy has developed and matured. But that's not all. The book presents a new set of challenges and questions for the quantitative literacy community, challenging the reader to tackle some of the following questions: What are new quantitative literacies? How should quantitative literacy be situated in interdisciplinary contexts? What is the interaction between social justice and quantitative literacy? Should quantitative literacy be focused on individualism or collectivism? Is quantitative literacy worth it (and if so, what are we doing to provide access to it)? The most exciting question is: what's next? This volume prepares the reader well to not only consider that question, but to play an active role in finding the answer. 


\section{References}

Bolker, Ethan and Maura Mast. 2016. Common Sense Mathematics. Washington, DC: MAAPress.

Byram, Michael. 1997. Teaching and Assessing Intercultural Communicative Competence. Clevedon, UK: Multilingual Matters.

Erickson, Ander W. 2017. "Rethinking the Numerate Citizen: Quantitative Literacy and Public Issues - Reply." Numeracy 10 (2): Article 13. http://doi.org/10.5038/1936-4660.10.2.13

Gee, James Paul. 2010. "A Situated Sociocultural Approach to Literacy and Technology." In The New Literacies: Multiple Perspectives on Research and Practice, edited by Elizabeth A. Baker, 165-193. New York: Guilford Press.

Gillman, R. 2006. "A Case Study of Assessment Practices in Quantitative Literacy”. Current Practices in Quantitative Literacy MAA Notes \#70. Gillman, ed. Washington DC: Mathematical Association of America.

Guinier, Lani, and Gerald Torres. 2002. The Miner's Canary: Enlisting Race, Resisting Power, Transforming Democracy. Cambridge, MA: Harvard University Press.

Hamman, Kira H. 2017. "Rethinking the Numerate Citizen: Quantitative Literacy and Public Issues - Discussion." Numeracy 10 (2): Article 12. http://doi.org/10.5038/1936-4660.10.2.12

Karaali, Gizem, Hernandez, Edwin H., and Taylor, Jeremy A. 2016. "What's in a Name? A Critical Review of Definitions of Quantitative Literacy, Numeracy, and Quantitative Reasoning," Numeracy 9 (1): Article 2. http://doi.org/10.5038/1936-4660.9.1.2

Madison, Bernard L. 2015. "Quantitative Literacy and the Common Core State Standards in Mathematics," Numeracy 8 (1): Article 11. http://doi.org/10.5038/1936-4660.8.1.11

RadicalMath, $\quad$ http://www.radicalmath.org/main.php?id=SocialJusticeMath (accessed June 23 2019)

Sons, L.R., ed. 1994. Quantitative Reasoning for College Students: A Complement to the Standards. Washington, D C: Mathematical Association of America.

Steen, L. A. (exec. ed.). 2001. Mathematics and Democracy: The Case for Quantitative Literacy. The Woodrow Wilson National Fellowship Foundation, National Council on Education and the Disciplines. http://www.maa.org/ql/mathanddemocracy.html

Vacher, H. L. 2014. "Looking at the Multiple Meanings of Numeracy, Quantitative Literacy, and Quantitative Reasoning." Numeracy 7 (2): Article 1. http://doi.org/10.5038/1936-4660.7.2.1 
Vacher, H. L. 2019. "The Second Decade of Numeracy: Entering the Seas of Literacy." Numeracy 12 (1): Article 1. http://doi.org/10.5038/19364660.11.1.1

Wallace, Dorothy. 2019. "Three Formative Questions in the Quantitative Literacy Movement." Numeracy 12 (1): Article 13. http://doi.org/10.5038/1936$\underline{4660.12 .1 .13}$ 